\title{
BEST PRACTICE PROCEDURES FOR MAKING DIRECT DRIVE CYLINDRICAL TARGETS FOR STUDIES OF CONVERGENT HYDRODYNAMICS
}

\author{
Norman Elliott, Cris W. Barnes, Steven H. Batha, Robert D. Day, Joyce Elliott, Peter Gobby, Veronica Gomez, \\ Douglas Hatch, Nicholas E. Lanier, Glenn R. Magelssen, Ruben Manzanares, Ron Perea, Timothy Pierce, \\ Gerald Rivera, David Sandoval, John M. Scott, Warren Steckle, David L. Tubbs \\ Los Alamos National Laboratory, Los Alamos, NM, 87545 USA \\ (505)667-1587nee@lanl.gov \\ Stephen Rothman, Colin Horsfield, A. Michael Dunne, Kenneth W. Parker \\ $A W E$, Aldermaston, Reading RG7 4PR, $U K$
}

\begin{abstract}
The production of cylindrical targets involves numerous steps. These steps are shared in common with many other types of Inertial Confinement Fusion (ICF) targets but no other single target encompasses such a wide range of fabrication techniques. These targets consist of a large number of individual parts, virtually all fabricated from commercially purchased raw material. As an example, the polystyrene used is synthesized in house from purchased monomer material. This material must be polymerized, purified, characterized and put into solution before it is even first used in the making of a target. Because virtually every manufacturing and assembly process we currently use is involved in the production of these targets, this paper is written as a way documenting the methods used.
\end{abstract}

\section{INTRODUCTION}

Using cylinders in hydrodynamic experiments allows the observation of interface motion along the axis but in a convergent geometry. Experiments using indirect drive in hohlraums on Nova ${ }^{1}$ and now using direct drive on OMEGA ${ }^{2}$ have studied low-order mode Rayleigh-Taylor growth at the ablation surface, weakly non-linear mode coupling, shock interactions at material interfaces, and Richtmyer-Meshkov turbulent mix all affected by Bell-Plesset convergent effects. Also detailed work on the techniques of comparison of hydrodynamic simulations to experimental measurements has been done using static targets. ${ }^{3}$ To achieve sufficient quality data for significant comparison to theoretical simulations, the target dimensions, densities, surfaces, and quality must be carefully controlled and measured. A previous description of the manufacture of cylinder targets for the indirect drive Nova experiments, concentrating on the machining of perturbations, has been published. ${ }^{4}$ Six campaigns for direct drive cylinders (DDCYLs) on the OMEGA laser over more than three years have generated a procedure for the "best practice" in making the polystyrene ablators, radiographic marker layers, and foam inserts.

The description of the targets and the experimental design has been published. ${ }^{2}$ In general the finished target consists of polystyrene foam of between $30-120 \mathrm{mg} / \mathrm{cm}^{3}$ density and $860 \mu \mathrm{m}$ nominal outer diameter. This $\mathrm{CH}$ foam has also been 
successfully replaced with fully deuterated foam. The foam goes inside a polystyrene ablator (cylinder) of 20-73 $\mu \mathrm{m}$ wall thickness, with the outer diameter from 900-1014 $\mu \mathrm{m}$ and $2250 \mu \mathrm{m}$ in length. At the interface of the ablator and the foam, in the central 500- $\mu \mathrm{m}$ region is a radiographic marker layer, sometimes applied to the outside of the foam but generally embedded in the ablator during manufacture. The target is completed with assembly of backlighter, image defining aperture and alignment fibers on a target mount. Figure 1 shows an exploded view of the parts of a typical DDCYL target.

\section{PLASTIC ABLATORS AND EMBEDDED MARKERS}

The primary ablator or pusher is a cylindrical shell of polystyrene wrapped around a marker layer at the inside edge. This shell is made by a sequence of steps of applying layers to a central sacrificial mandrel, machining each layer, and concluding by chemically leaching away the mandrel. These steps are now described in sequence.

The mandrels are machined out of silicon-bronze rods placed in a brass base used for precision installation on the diamond turning lathe. New bases must be annealed by bringing them up to the highest processing temperature they will see during subsequent steps, typically $200^{\circ} \mathrm{C}$ for an hour, and then they must be well cleaned before mandrels are put in them. Originally aluminum (ASTM 6061-T6) had been used as the mandrel material, subsequently leached by $\mathrm{NaOH}$. We now use silicon bronze mandrels that are leached by a mixture of $50 \%$ concentrated nitric acid and 50\% distilled water. The silicon bronze is more homogenous, without the insoluble inclusions or precipitates of the aluminum. This allows machinists to achieve a better surface finish and also eliminates the insoluble black precipitates found when the aluminum was leached. The mandrels are made 4-mm long to insure a uniform coating of the polystyrene layer. The mandrel must be removed and replaced many times on the diamond turning lathe to allow the formation of marker bands and ablator layers. An indicator band on the base is used by the machinist allowing recentering of the mandrel each time it goes back onto the lathe. This assures that all machined layers are concentric. When finished machining, the mandrels are cleaned with methanol, Excaliber ${ }^{\circledR}$, ethanol, and finally again with methanol to remove any machining grease. The inner

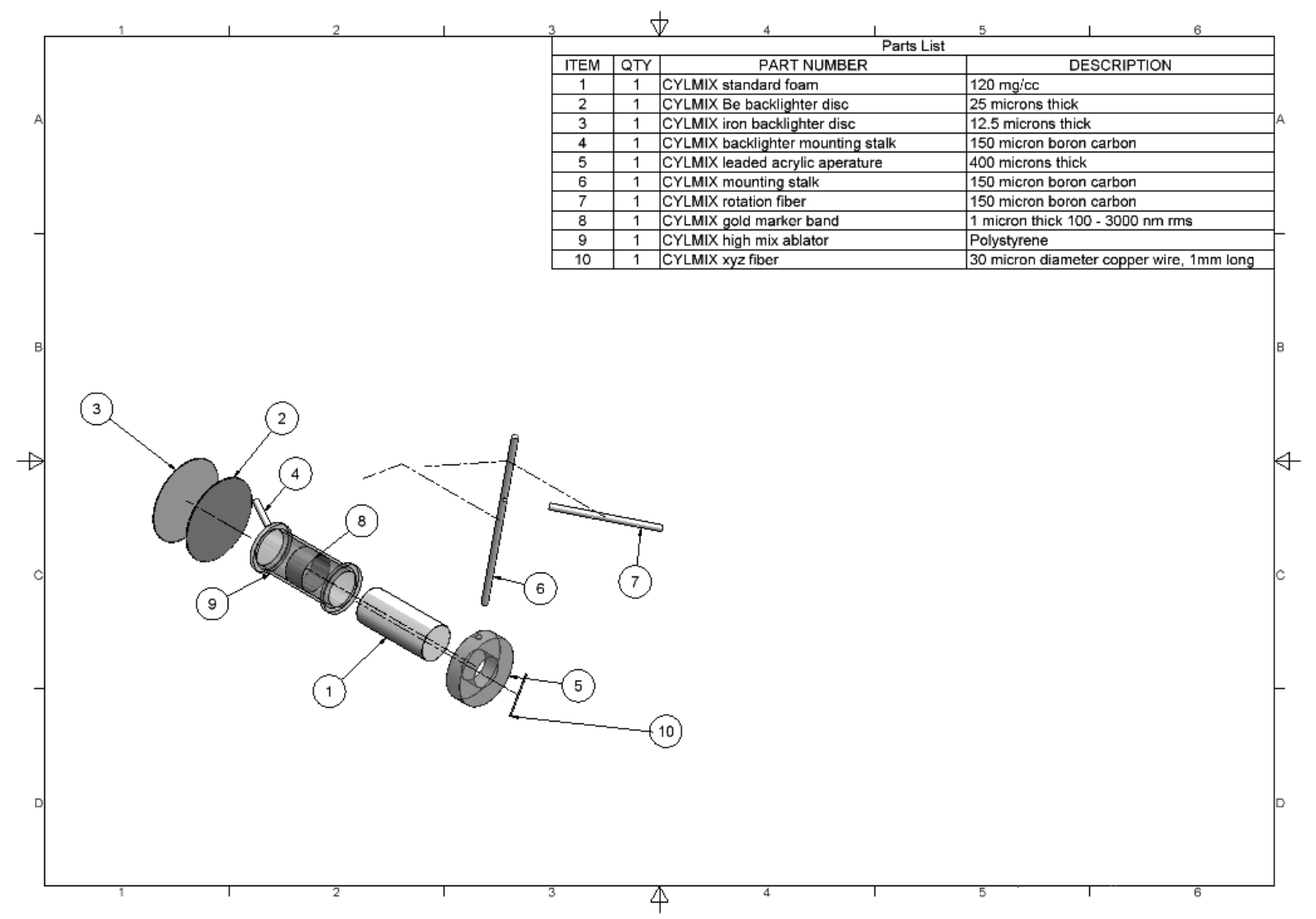

Figure 1: CAD drawing of exploded DDCYL assembly 
diameter of the final cylinder is determined by measuring the diameter of the mandrel using a laser micrometer. Individual targets are then tracked by a number on each mandrel base.

Many targets make use of a poly(2,6dichlorostyrene) marker layer. This layer produces radiographic contrast during the laser experiment without producing a significant density change. All polystyrene layers are made by dipping the mandrels in the appropriate polystyrene dissolved in a solvent. The polymers are synthesized in house. A fresh stock of polymer is made for each campaign, using a bulk polymerization process that applies a free radical initiator to the commercial monomer. High average molecular weight polymer works better, in the range of $5 \times 10^{5}-10^{6}$ daltons. Low average molecular weight material has been tried. This material tended to be harder to machine and more likely to craze. Toluene is used as the solvent; adding correct amounts of it is important to control of the viscosity of the solution in which the mandrel is dipped. Thinner, with lower viscosity, is better, as it doesn't tend to trap bubbles under each layer. The drawback is that each dip layer is thinner and more dips must be done to build up thick layers. The solvent evaporates and the viscosity changes, making dipping an art.

To apply the polystyrene coating the mandrel is dipped in the polystyrene solution, but not past the diamond turned portion of the mandrel. It is air-dried 15 minutes upside down in a small bottle, and then for 2-3 days in the open. This process is repeated to build up the required thickness, though the chlorinated marker layers of eventual $4 \mu \mathrm{m}$ thickness usually require only one dip. Then the plastic is annealed. Control of this process is still not complete. We desire to drive out solvent from the plastic and take the polymer past its glass transition temperature, but in such a way as not to leave trapped bubbles. However, we have found that annealing for many weeks appears to overdry the plastic and make it too brittle for subsequent machining. The process that works best is a gradual ramp up in a Fisher programmable oven over 7-9 days, increasing the temperature by about $10-20^{\circ} \mathrm{C}$ every day or so. The glass transition temperature for the dichlorostyrene is $167^{\circ} \mathrm{C}$, and present best practice is to anneal the marker layer to $170^{\circ} \mathrm{C}$ to assure it has reached the glass transition temperature. The mandrel with marker material is then cooled in a closed oven for over a day.

The annealed plastic is then machined to length and radius. Only diamond tool bits are used to machine the polystyrene. This includes even any roughing out process, where use of high-speed steel bits induces stress in the plastic. The $500 \mu \mathrm{m}$-long marker region should be placed relatively centered along the mandrel, so that the eventual end of the polystyrene pusher should be over $500 \mu \mathrm{m}$ from the mandrel end. The precision bases are used to re-center the piece so that the $4 \mu \mathrm{m}$-thick marker bands are concentric with the original machining of the mandrel. After machining, scanning electron microscope (SEM) images of the edge of each marker at four different azimuthal locations are taken. Bands are rejected if they show cracking, chunks missing, or flaring of the ends. The thickness and uniformity of the bands can be determined at the same time to typically $\pm 0.5 \mu \mathrm{m}$.

Glow discharge plasma is then used to cross-link the polystyrene marker band. 10 minutes in a $13 \mathrm{~Pa}$ argon DC plasma is used. This may cause a faint yellowish color on the marker that appears benign and actually aids later observation of the marker for alignment purposes. The color is probably the result of unintended sputtering of the brass base or silicon bronze mandrel itself. This cross-linking further reduces the possibility of solvating the marker band during further polystyrene dipping.

The dichlorostyrene marker is then overcoated with parylene-N to protect the marker from the solvent in the dipping step for the ablator. A layer about 3.5$4 \mu \mathrm{m}$ is put on. It is treated in the computer simulations just as part of the $\mathrm{CH}$ ablator.

For turbulent mix studies, alternative markers are made of metals put on the mandrel. Either electroplated gold or nickel, or physical vapor deposition (PVD) of aluminum have been used. Measurements of the material thickness layer are made by differential measurements of the mandrel and marker diameters with a laser micrometer with $\pm 0.1 \mu \mathrm{m}$ precision. The electroplated material is back machined to length, but not over the marker; the PVD aluminum has its outer diameter and surface roughness created by machining. The strength of these markers increases dramatically (as the third power) with their thickness. Very thin $(1 \mu \mathrm{m})$ gold markers tend to "buckle" under pressure from the ablator shrinkage when the mandrel is leached out.

The main $\mathrm{CH}$ ablator is put on by dipping and annealing as with the dichlorostyrene markers. Similar comments apply about starting with new solution with high molecular weight (varying widely but averaging about $6 \times 10^{5}$ daltons) and achieving the correct viscosity. Toluene is used as the solvent. After each dip the target is air dried for about 30 minutes and this process is repeated until the minimum required coating 
thickness is achieved. The resulting lop-sided coating is then back-machined to a diameter a little larger than finally desired. The target is then annealed by a similar ramp-up procedure over several days. The glass transition temperature for normal polystyrene is $100^{\circ} \mathrm{C}$, and eventually we take the entire finished target up over this temperature. Best results are seen after going to $120^{\circ} \mathrm{C}$ for no more than an hour. The parts are then again oven cooled to room temperature.

The main ablator can then be machined, again using only sharp diamond bits even for roughing. At the ends of the cylinder, larger diameter "spools" are machined to aid attachment of other hardware to the target. The machining of these spools requires that two separate diamond tools be mounted and used. For ablative Rayleigh-Taylor work, external machined perturbations are only placed over the marker region on the outside of the ablator using a fast tool servo. ${ }^{4}$ Contact profilometry using an air bearing LVDT is then performed to characterize the perturbations.

A key recurring issue has been damage to the dichloropolystyrene marker layer during application of the outer polystyrene ablator. This is a result of the solvent used to deposit the outer ablator layer partially redissolving the finished dichloropolystyrene marker band. Raising the marker band to its glass transition temperature, performing a glow discharge plasma cross-linking, and putting a sufficiently thick (and clean) parylene coating over it have all contributed to more successful chlorine bands.

After dipping, annealing, machining the outer ablator and leaching, the presence of the chlorine band can be determined by $\mathrm{x}$-ray fluorescence

measurements. The measurements are done by passing the $\mathrm{x}$-ray fluorescing beam through the unchlorinated polystyrene ablator wall using an x-ray microfocus machine. This configuration limits the sensitivity and maximum wall thickness that can be used. The attenuation length ( $1 / \mathrm{e})$ for chlorine $\mathrm{x}$-rays in full density polystyrene is $75 \mu \mathrm{m}$. This is roughly the practical limit for the wall thickness of the cylinders using this technique. By positioning the $\mathrm{x}$-ray illumination on different portions of the marker band and rotating the band in front of the source a qualitative feel for marker band uniformity combined with wall uniformity can be obtained. This step is done to assure the presence of the marker band after leaching. It was found, in some instances, that the marker band would craze and fall out in pieces during the leaching process. Even though the marker band was missing it could not be detected optically because the shape of the marker band was replicated in the ablator and gave the optical appearance of the band being present. A similar technique is used to quantitatively determine the gold thickness on "high mix" targets. These targets have the gold directly deposited on the outside of the central foam. Standards of known thickness deposited on optical flats allow calibration of the method.

\section{CENTRAL FOAMS}

To avoid having a vacuum and provide hydrodynamic backpressure, foam is inserted down the middle of the ablator shell. It is $2000 \mu \mathrm{m}$ long so that the ablator hangs over its end and prevents direct illumination of the foam end. The polystyrene foams are made to the requested density and then filled with $\mathrm{BRIJ}^{\circledR}$ to allow machining. ${ }^{5}$ After machining the $\mathrm{BRIJ}^{\circledR}$ is leached out of the foam at $50^{\circ} \mathrm{C}$ for 4 hours in ethanol in an explosion-safe oven. The foam pieces are found to shrink approximately $1 \%-2 \%$ after leaching, and must be machined slightly oversize to compensate.

Some targets have used physical vapor deposition of gold directly onto the foam for a marker. The foam is masked to allow gold only over the required $500 \mu \mathrm{m}$-long marker region. The thickness of the gold is measured using quantitative $\mathrm{x}$-ray fluorescence (accurate to $\pm 5 \%$ ) and/or radiography. Scanning electron microscope images of the surface are taken.

Double shell targets (another variation of the same general target design) are manufactured by drilling a hole into the central foam before the BRIJ ${ }^{\mathbb{R}}$ is leached. A solid cylinder (wire) of correct radius and length is inserted and centered in the foam. The final assembly should undergo static radiography in two orthogonal views to confirm correct alignment and dimensions (see Figure 2). 


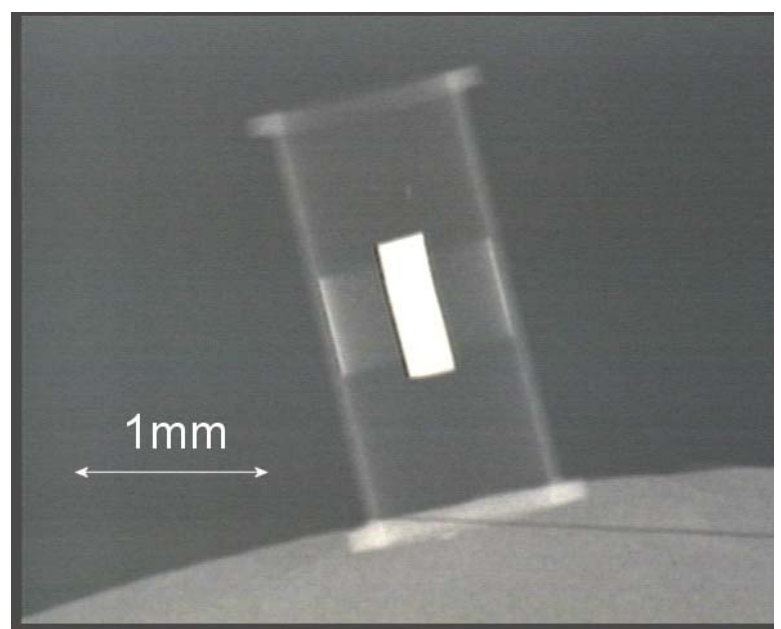

Figure 2: Static radiograph of double shell target showing alignment of internal wire to the cylinder outside and marker band.

After leaching both the polystyrene cylinder assembly and the foam, there is some shrinkage. The targets tend to be rapidly assembled at this point and detailed information on the time history of the shrinkage is not available. The authors believe most of the shrinkage occurs within a few minutes to an hour after leaching; afterward the targets are demonstrably stable in their dimensions for over a year at a time.
Care must be taken in inserting the foam into the cylinder to best match sizes and reduce any vacuum region between the ablator and foam and to prevent damage to the marker layer at the interface.

\section{DIMENSIONAL MEASUREMENTS AND METROLOGY}


It is important to measure and document the values as well as uncertainties in all target dimensions. This includes densities, marker thickness, length, and composition, and ablator radius and thickness, as well as target assembly angles and locations of alignment fiducials. The densities of the solid polystyrene have been determined from a density gradient column to $\pm 5 \%$ one-sigma uncertainty. Foam material density is calculated from measured volume and weight from a microbalance. Other dimensional measurements have been described above in their respective place in the processing. Because of shrinkage after leaching, final ablator radii must be determined by optical shadowography or microscopy after assembly with at best $\pm 1 \mu \mathrm{m}$ accuracy. The characterization of the surface roughness is discussed in another paper. ${ }^{6}$ Final documentation for each target includes dimensional metrology, surface roughness data, profilometry traces of perturbed targets, SEMs of markers or foams, $\mathrm{x}$-ray fluorescence values, and assembly photographs.

\section{FINAL TARGET ASSEMBLY}

With completed cylinders in hand, final targets are made by mounting on stalks, putting on backlighters and radiography apertures and alignment fibers. Angles and physical dimensions are determined using a so-called Powell scope, an optical microscope connected to a four-axis ( $\mathrm{X}$ and $\mathrm{Y}$ and two angles) a.

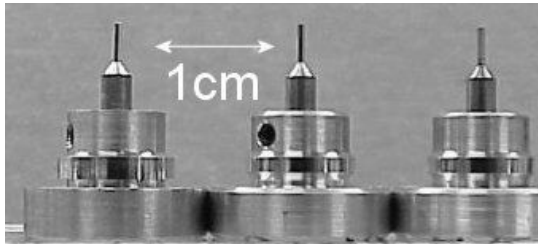

c.
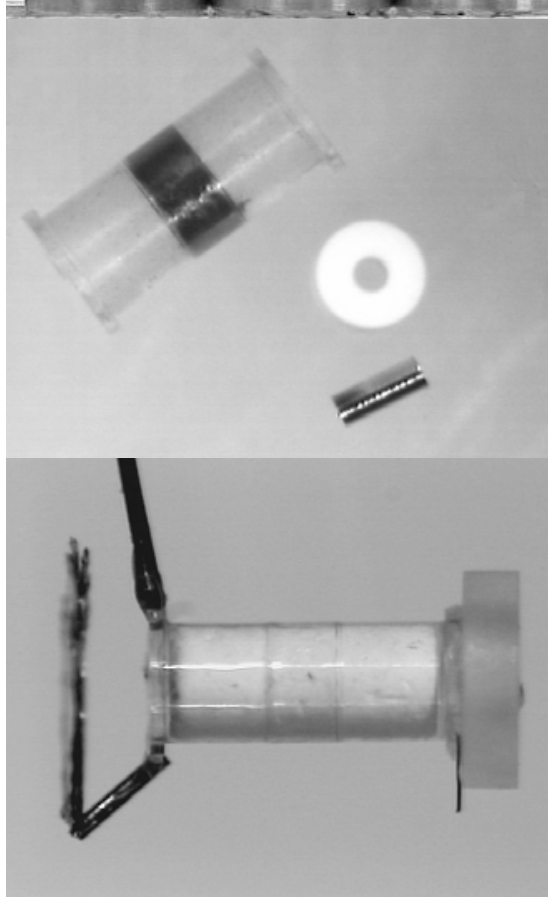

b.

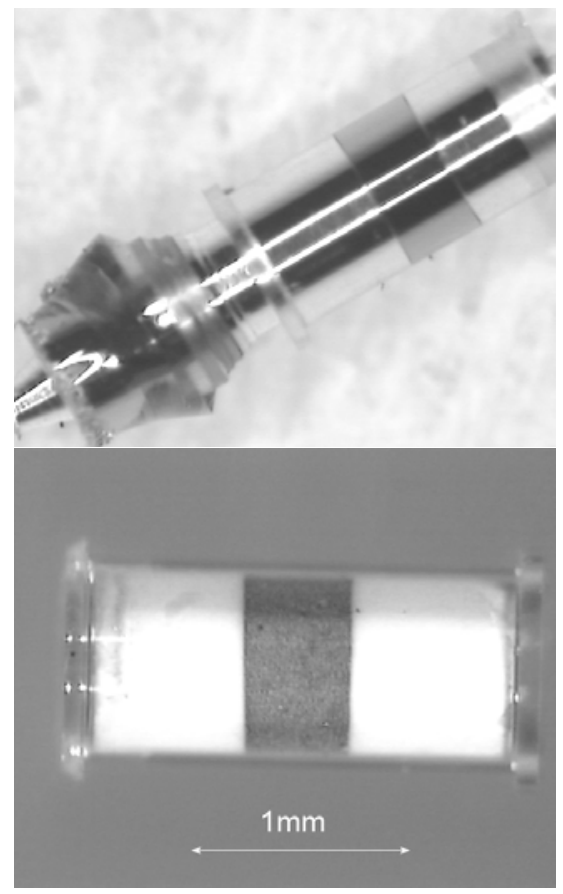

Figure 3: Assembly photos. a.) mandrels on bases ready for coating b.)coated mandrel with Ni marker band ready for leaching c.)pieces of double shell target ready for assembly d.) assembled Au "high mix" target e.)finished "low mix" target 
alignment system. This metrology can typically measure dimensions to $\pm 5 \mu \mathrm{m}$ and $\pm 0.1^{\circ}$, and allows final target alignment in the OMEGA target chamber to about $30 \mu \mathrm{m}$ and $\pm 0.3^{\circ}$ accuracy. Figure 3 shows photographs of the assembly of a typical target.

\section{SUMMARY}

The campaign to build direct drive cylindrical targets has continued for a number of years. Typical of this work, numerous small incremental improvements in fabrication have occurred in this time. This has resulted in the current state of the art as described in this paper. Differing from most of our work, these targets encompass virtually every fabrication method we have at our disposal. This is especially surprising after looking at the conceptually simple design of the target. As a consequence, this design presents a perfect example of our ability to produce a target of critically defined characteristics that will allow quantitative comparison to numerical simulations.

\section{REFERENCES}

(1)W.W.HSING, et al., "Rayleigh-Taylor

Instability Evolution in Ablatively Driven Cylindrical Implosions," Phys. Plasmas 4, 1832 (1997);

W.W.HSING AND N.M. HOFFMAN, "Measurement of Feedthrough and Instability Growth in RadiationDriven Cylindrical Implosions, ” Phys. Rev. Lett. 78, 3876 (1997); S. R. GOLDMAN et al., "Production of

Enhanced Pressure Regions due to Inhomogeneities in Inertial Confinement Fusion Targets," Phys. Plasmas 7, 2007 (2000).

(2) C. W. BARNES et al., "Experimental Configuration of Direct Drive Cylindrical Implosions on the OMEGA Laser," Rev. Sci. Instrum 70, 417

(1999); D. L. TUBBS et al., "Direct Drive Cylindrical Implosion Experiments: Simulations and Data," Laser

Particle Beams 17, 437 (1999); D. L. TUBBS et al.,

“Cylindrical Implosion Experiments Using Laser

Direct Drive,"” Phys. Plasmas 6, 2095 (1999) 2095; C.

W. BARNES et al., "Observation of Mix in a

Compressible Plasma in a Convergent Cylindrical

Geometry," (submitted to Phys. Rev. Letters, 2001).

(3) J. M. SCOTT et al., "Radiographic Image Analysis of Cylindrical Implosion Experiments," Rev.

Sci. Instrum. 72, 643 (2001).

(4)MICHELE H. MILLER, KENNETH P.

GARRARD, THOMAS A.DOW, LAUREN W.

TAYLOR, Precision Engineering 16:1, 42 (1994); B.

H. JARED et al., "Fabrication of Hydrodynamic

Instability Targets," Fusion Technology 31501

(1997).

(5) J.M. WILLIAMS, M. H. WILKERSON, A. J. GRAY, "Emulsion Stability and Rigid Foams From Styrene or Divinylbenzene Water-In-Oil Emulsions" Langmuir Feb 1990; vol.6, no.2, p.437-444.

(6) CRIS W. BARNES, R. D. DAY, N. E. ELLIOTT, et al., "Characterization of Surface Roughness and Initial Conditions for Cylindrical Hydrodynamic and Mix Experiments," these proceedings. 